This article was downloaded by: [CAS Consortium]

On: 24 April 2009

Access details: Access Details: [subscription number 909168890]

Publisher Taylor \& Francis

Informa Ltd Registered in England and Wales Registered Number: 1072954 Registered office: Mortimer House, 37-41 Mortimer Street, London W1T 3JH, UK

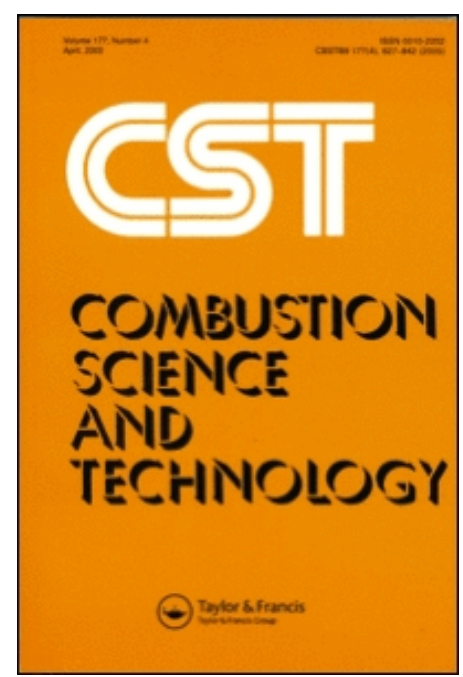

Combustion Science and Technology

Publication details, including instructions for authors and subscription information:

http://www.informaworld.com/smpp/title content=t713456315

\title{
STUDY OF GAS COMBUSTION IN A VENTED CYLINDRICAL VESSEL
}

Jun $\mathrm{Hu}{ }^{\text {a; }}$ Yikang Pu a; Fu Jia a; Jozef Jarosinski ${ }^{\text {b }}$

${ }^{a}$ Institute of Mechanics, Chinese Academy of Sciences, Beijing, China ${ }^{b}$ Department of Heat Technology and

Refrigeration, Technical University of Lodz, Lodz, Poland

Online Publication Date: 26 January 2005

To cite this Article Hu, Jun, Pu, Yikang, Jia, Fu and Jarosinski, Jozef(2005)'STUDY OF GAS COMBUSTION IN A VENTED

CYLINDRICAL VESSEL',Combustion Science and Technology,177:2,323 - 346

To link to this Article: DOI: $10.1080 / 00102200590900499$

URL: http://dx.doi.org/10.1080/00102200590900499

\section{PLEASE SCROLL DOWN FOR ARTICLE}

\footnotetext{
Full terms and conditions of use: http://www.informaworld.com/terms-and-conditions-of-access.pdf

This article may be used for research, teaching and private study purposes. Any substantial or systematic reproduction, re-distribution, re-selling, loan or sub-licensing, systematic supply or distribution in any form to anyone is expressly forbidden.

The publisher does not give any warranty express or implied or make any representation that the contents will be complete or accurate or up to date. The accuracy of any instructions, formulae and drug doses should be independently verified with primary sources. The publisher shall not be liable for any loss, actions, claims, proceedings, demand or costs or damages whatsoever or howsoever caused arising directly or indirectly in connection with or arising out of the use of this material.
} 


\title{
STUDY OF GAS COMBUSTION IN A VENTED CYLINDRICAL VESSEL
}

\author{
JUN HU \\ YIKANG PU \\ FU JIA \\ Institute of Mechanics, Chinese Academy of Sciences, \\ Beijing, China
}

JOZEF JAROSINSKI* Department of Heat Technology and Refrigeration,
Technical University of Lodz, Lodz, Poland

\begin{abstract}
Complicated interaction of a flame front with a turbulent flow induced by venting is studied during combustion of the stoichiometric propane/air mixture in a relatively large vented cylindrical vessel. Flame position, its shape, and combustion pressure were measured as a function of time and vent parameters. The experimental data were used to verify numerical simulation of the combustion process. The proposed numerical model satisfactorily simulates the main features of combustion in a closed and vented vessel such as flame configuration, flow and temperature fields, and pressure variation pattern. Simulated velocity and temperature distribution are very useful pieces of information because they are not available from experiments.
\end{abstract}

Keywords: vented combustion, numerical simulation, flame-flow interaction

Received 21 January 2004; accepted 11 August 2004.

The authors would like to acknowledge the financial support provided by National Nature Science Foundation (No. 19772060) and the Knowledge Innovation Program of the Chinese Academy of Sciences (No. KJCX2-SW-L05). Part of the present study was performed under the Polish and Chinese Scientific Exchange Program. The Program supported the scientific stay of the first author at the Technical University of Lodz.

*Address correspondence to jarosin@mail.p.lodz.pl 


\section{INTRODUCTION}

The venting technique is a popular and effective prevention method to reduce explosion hazard in industrial containers of flammable gases, liquids, and powders (Eckhoff, 1991). Important parameters of venting design include venting position, its cross-sectional area, and venting pressure. Determination of these parameters requires understanding of venting processes for a given vessel geometry under considered boundary conditions. Especially important is to understand the interaction process of the flame front with turbulent flow induced by venting.

The most advanced venting design methods so far applied in safety engineering are those based on so-called heat balance models (Canu et al., 1991; Eckhoff, 1991; Nagy and Verakis, 1983; Swift and Epstein, 1987). In these methods, pressure variation and venting flow are inferred from calculation of heat, mass, and momentum balances between burned and unburned regions (Canu et al., 1991; Cooper et al., 1986; McCann et al., 1985). However, many key issues remain open to further solutions.

Besides, relevant experimental data are mostly limited to smallaspect-ratio vessels usually spherical in shape (Cooper et al., 1986; McCann et al., 1985). A special deficiency of experimental observations exists for elongated large-aspect-ratio vessels, which are typical for industrial applications. Flame propagation in such vessels has been proved to be very different from those with small-aspect-ratio spherical vessels (Markstein, 1964; $\mathrm{Pu}, 1$ 1987; Starke and Roth, 1989).

The present study reports some direct measurements of flame propagation and pressure variation in a vented cylindrical tube characterized by an aspect ratio equal to 5.6. Observed phenomena are analyzed from the point of view of interaction between venting induced flow and ongoing combustion process. Numerical simulation applied to analysis of the observed processes appeared quite satisfactory in reproducing the main features of experimentally observed phenomena. It is expected that the observations, measurements, and simulations presented in the present paper will improve our understanding of the combustion mechanism in vessels with venting.

\section{EXPERIMENTAL DETAILS}

The experimental apparatus used in the present study is shown in Figure 1. Experimental facilities include a cylindrical venting tube, mixture feeding system, igniter and its controller, vent opening system, pressure transducer, 


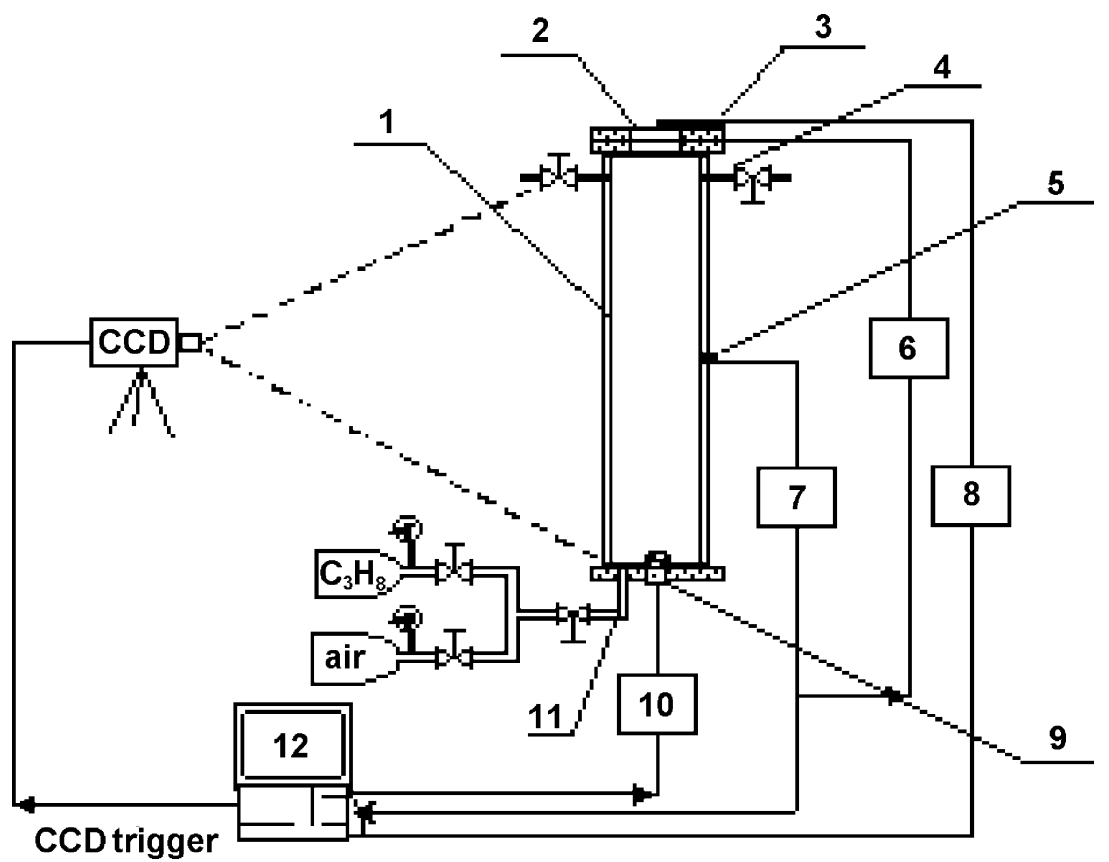

Figure 1. Schematic of the experimental apparatus: 1, cylindrical vessel; 2, vent foil or cover of flange plate; 3 , venting detector; 4, outlet; 5 , pressure transducer; 6 , venting control system; 7, amplifier; 8, venting detecting system; 9, igniter; 10, ignition control system; 11, inlet; 12 , computer.

high-speed charge-coupled device camera, and data transmission system (data storage system, signal amplifier, and process timer).

Both constant volume and venting combustion experiments were conducted in a cylindrical tube $1 \mathrm{~m}$ long and $0.18 \mathrm{~m}$ in diameter. The tube was built of transparent perplex glass to make visualization possible. A circular vent was located at the center of the top plate of the tube, opposite to its bottom plate with igniter. Vents with three different diameters - 50, 80, and $100 \mathrm{~mm}$-were tested. The corresponding vent ratio $\delta$ (the ratio of a vent area to the cross-sectional area of a vessel) is 7.7, 19.7 , and $30.8 \%$, respectively. A thin membrane made of plastic foil covered the vent. To ensure an immediate venting at designed time and pressure, a copper wire was stuck on the membrane surface so that signaled electric current can melt the membrane and vent the tube.

The fuel/air mixtures were carefully prepared by blending fuel and air. The output of each gas was measured by means of rotameter-type 
Table 1. Experimental parameters

\begin{tabular}{lccc}
\hline Mixtures & Initial pressure (Pa) & Vent diameters & Venting pressure (MPa) \\
\hline $9.5 \% \mathrm{CH}_{4} /$ Air & 101,325 & $\phi 50, \phi 80, \phi 100$ & $0.01-0.10$ \\
$4.1 \% \mathrm{C}_{3} \mathrm{H}_{8} /$ Air & 101,325 & $\phi 50, \phi 100$ & $0.005-0.460$ \\
\hline
\end{tabular}

flow meters. Before each experiment at least $10 \mathrm{~min}$ were allowed for ensuring the quiescent state of the gas mixture in the vessel at the ambient pressure of $101,325 \mathrm{~Pa}$.

A piezoelectric transducer with a sensitivity of $207 \mathrm{mv} / \mathrm{MPa}$ was set on the sidewall of the vessel to measure pressure history. The transducer signal was amplified and recorded by a multichannel recorder at a sampling rate of $2 \mathrm{~ms}$.

To record the flame propagation history, a high-speed camera system was employed. The camera recorded 500 color frames per second, sufficiently fast to register the flame propagation process.

A computer program controlled experimental procedures. It started with pressure and visualization recording systems. Then ignition was triggered by a program signal. The earlier designated value of pressure inside the tube (venting pressure) gave out a signal to the electrical circuit and vented the tube.

Stoichiometric mixtures of methane and propane with air were used in experiments. Experimental parameters are listed in Table 1. In the present study, the experiments are concentrated on combustion of the propane/air mixture.

\section{RESULTS AND DISCUSSION}

\section{Closed-Tube Combustion}

From a safety consideration standpoint, the combustion experiments in a closed tube were conducted up to a pressure not higher than $0.46 \mathrm{MPa}$ (the tube was made of perplex glass). Such pressure was high enough to reveal the most characteristic features of closed-tube combustion before its venting. Data from observation of flame behavior during its propagation in a closed vessel were used for comparison with experiments in a venting vessel.

Usually engineering venting pressure is designed below $0.1 \mathrm{MPa}$ (e.g., is much lower than $0.46 \mathrm{Mpa}$ ). 


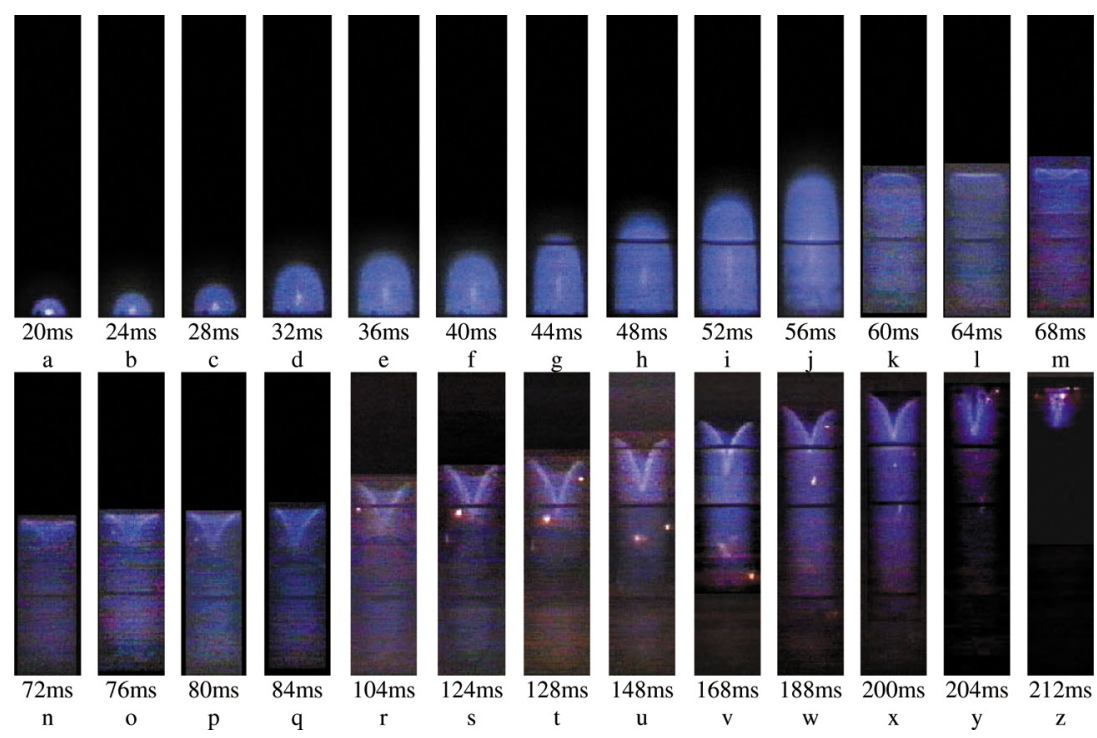

Figure 2. Flame position and its shape as a function of time (full-length tube). Combustion of propane/air mixture $\left(4.1 \% \mathrm{C}_{3} \mathrm{H}_{8}\right)$ in a closed tube.

History of flame propagation in propane/air mixture with concentration $4.1 \% \mathrm{C}_{3} \mathrm{H}_{8}$ is shown in Figure 2. An axial propagation velocity of the flame leading point deduced from this record is shown in Figure 3. Measured pressure history is shown in Figure 4. It is seen from this figure that the pressure variation curve is cut off at the venting instant, because further combustion was no longer in a closed tube. The dashed line in Figure 4 is the rate of pressure rise $(\mathrm{d} p / \mathrm{d} t)$, which is derived from the pressure curve.

It is worth it to pay attention to the following phenomena characteristics for closed-tube combustion.

- Three types of flame configuration can be recognized from the history of flame propagation shown in Figure 2:

- Flame with a smooth spherical and then elongated ellipsoidal surface accelerating from the ignition point to the instant of its contact with the vessel sidewalls (at the moment of $t^{*}=52 \mathrm{~ms}$ after ignition),

- Flame with a relatively stable flat surface retaining approximately the same position from $t^{*}=52 \mathrm{~ms}$ to $t^{* *} \cong 76 \mathrm{~ms}$, and 


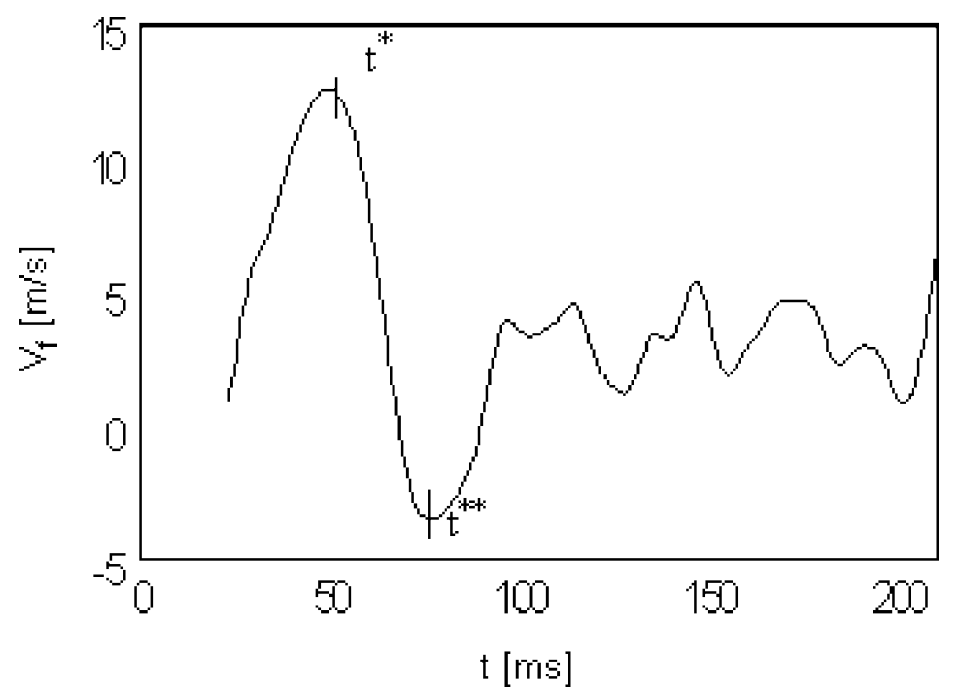

Figure 3. Velocity of flame-front leading point as a function of time. Combustion of propane/air mixture $\left(4.1 \% \mathrm{C}_{3} \mathrm{H}_{8}\right)$ in a closed tube.

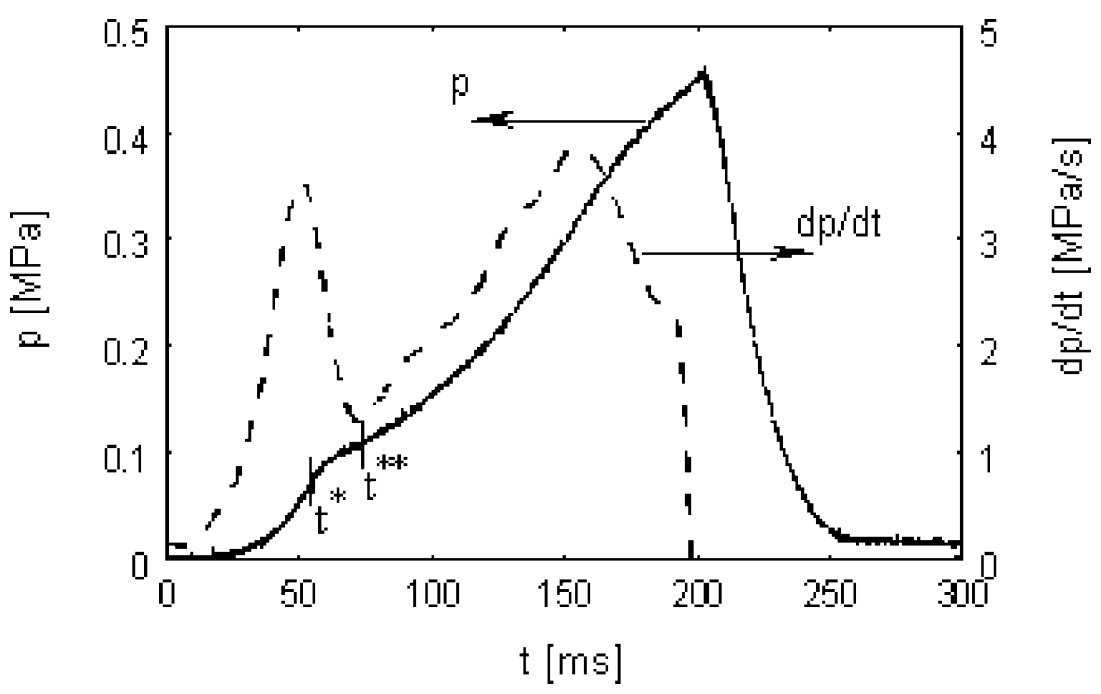

Figure 4. Pressure and rate of pressure rise as a function of time. Combustion of propane/air mixture $\left(4.1 \% \mathrm{C}_{3} \mathrm{H}_{8}\right)$ in a closed tube. 
- Typical "tulip flame" with cusped shape of the flame-front surface and the cellular shape in the last phase of its propagation (from $t^{* *} \cong 76 \mathrm{~ms}$ to the end of combustion at $t=212 \mathrm{~ms}$ ).

- Analysis of the flame propagation velocity curve in Figure 3 shows that the maximum propagation velocity appears to be close to the instant $t^{*}$.

- Analysis of the rate of pressure rise $(\mathrm{d} p / \mathrm{d} t)$ in Figure 4 indicates that the first peak of $\mathrm{d} p / \mathrm{d} t$ reaches its maximum value also at the instant $t^{*}$.

It is evident from these observations that time $t^{*}$ separates the first type of flame configuration from the two others. Flame propagation at $t<t^{*}$ can be regarded as a result of an adiabatic combustion process. In this stage of combustion, the flame front is driven by thermal expansion. This expansion breaks down as the flame reaches the sidewalls. The sudden collapse of the flame surface area results in deceleration of the flame front at its leading point (see Figure 3) and in a break of the rate of pressure rise (see Figure 4). A similar interpretation of combustion phenomena in a closed tube can be found in many studies (e.g., Gonzales, 1996; Gonzales et al., 1992; Markstein, 1964; Starke and Roth, 1986;). According to Gonzales (1996), the formation of the tulip flame results from strong deceleration of its central part during the contact of the flame with the sidewalls, from accelerated flow in the zone wedged by the flame and the walls and reverse flow in the central region. In other words, a tulip flame is generated from the flat part of the flame front under the influence of hydrodynamics. During the formation and collapse of the tulip-flame, the flame surface undergoes soft pulsations due to the acoustic waves. The cellular shape of the flame observed in the last phase of its propagation results from the interaction with acoustic waves (Gonzales, 1996). There are also other opinions on the tulipflame formation mechanism. According to some of them, the formation of the tulip flame is a manifestation of Taylor instability driven by the deceleration of the flame tip (Clanet and Searby, 1996).

\section{Vented Tube Combustion}

Vent ratios $\delta=7.7,19.7$, and $30.8 \%$ were tested. It was found in experiments that observed phenomena in a vessel with the medium vent ratio $\delta=19.7 \%$ were very similar to those in a vessel with vent ratio $\delta=7.7 \%$. It was found in the experiments that the history of flame development and flame behavior in a tube with medium vent ratio, $\delta=19.7 \%$, was 
qualitatively similar to that in a tube with vent ratio $\delta=7.7 \%$. For this reason, the experimental results only for two vent ratios, $\delta=7.7$ and $30.8 \%$, with different mechanisms of flame development are presented in this paper. Helmholtz instability was not observed during the experiments.

Vent Diameter $50 \mathrm{~mm}(\delta=7.7 \%)$. Pressure history and velocity variation of the flame-front leading point as a function of time are shown in Figures 5 and 6 for different venting overpressures from 0.02 through $0.04 \mathrm{MPa}$ and 0.07 to $0.18 \mathrm{MPa}$. The history of flame propagation for venting overpressures of 0.02 and $0.18 \mathrm{MPa}$ are shown in Figures 7 and 8, respectively. It is seen from Figure 5 that all curves with venting overpressure below $0.07 \mathrm{MPa}$ belong approximately to one group, which can be recognized as low venting pressure curves. On the other hand, the overpressure curve ( $0.18 \mathrm{MPa})$ can be considered a high venting pressure curve.

The history of flame propagation related to venting overpressure 0.04 MPa is shown in Figure 7. The pressure curve corresponding to this history in Figures 5 and 6 is indicated by the letter b.

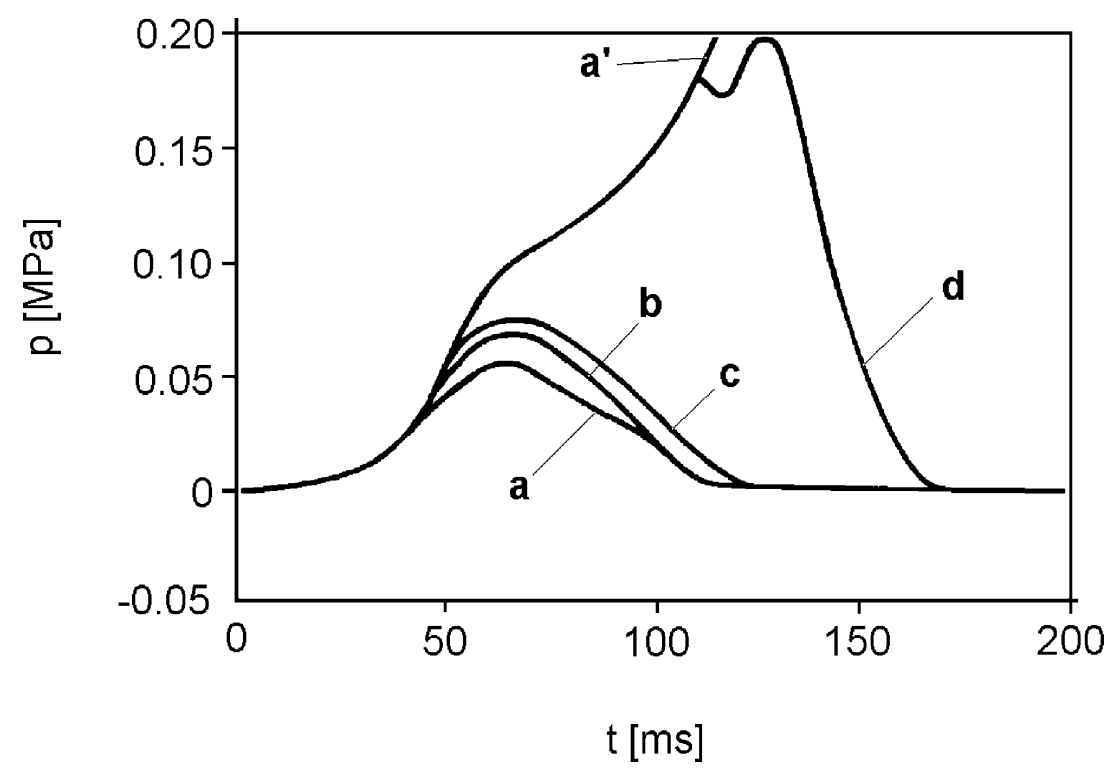

Figure 5. Pressure as a function of time in a tube with small vent diameter of $50 \mathrm{~mm}(\delta=$ $7.7 \%$ ) for different values of overpressure: $a^{\prime}$, closed tube combustion; a, $p_{v}=0.02 \mathrm{MPa}$; $\mathrm{b}, p_{v}=0.04 \mathrm{MPa}$;,$p_{v}=0.07 \mathrm{MPa}$;,$p_{v}=0.18 \mathrm{MPa}$. Combustion of propane/air mixture $\left(4.1 \% \mathrm{C}_{3} \mathrm{H}_{8}\right)$. 


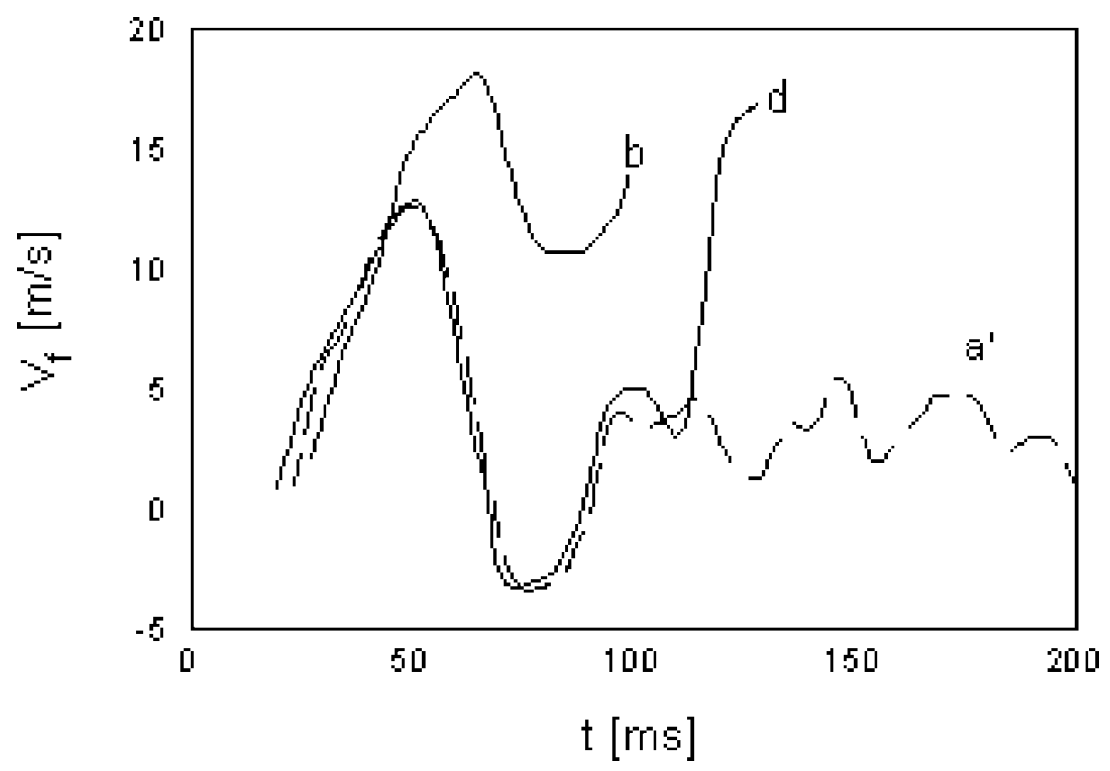

Figure 6. Velocity of flame-front leading point as a function of time for closed-tube combustion and venting combustion with $\delta=7.7 \%$ : $\mathrm{a}^{\prime}$, closed-tube combustion; $\mathrm{b}, p_{v}=0.04 \mathrm{MPa}$; $\mathrm{d}, p_{v}=0.18 \mathrm{MPa}$. Combustion of propane/air mixture $\left(4.1 \% \mathrm{C}_{3} \mathrm{H}_{8}\right)$.

The flame front in a tube with low venting pressure propagates, preserving its curved shape all the time to a distance much longer than that characteristic for closed-tube combustion. At the moment of opening of the vent, the propagation velocity attains its maximum value for the conditions of closed-vessel combustion (approximately $10 \mathrm{~m} / \mathrm{s}$ ), and after that it continues to increase its velocity up to $\approx 18 \mathrm{~m} / \mathrm{s}$ at a distance of 0.75 of the tube length. At that instant, the flame-front shape resembles a lotus flower, which is different from that well known from the closedtube combustion experiments as a tulip flame. Different flame shape most probably results from changes in a flow field interacting with the flame. It is seen from Figures 5, 6, and 7 that at the final stage of combustion the fluctuating flame moves to a venting orifice at a speed higher than $10 \mathrm{~m} / \mathrm{s}$. Finally, it attains the vent and the combustion process is finished.

Finally, it can be concluded that the low venting pressure at the small vent ratio $\delta=7.7 \%$ contributes to very early start of evacuation of a mixture from the tube with rather small discharge rate. Outflow of the mixture through the vent allows the flame to extend a distance of its uninterrupted propagation with curved ellipsoidal shape. The combustion 


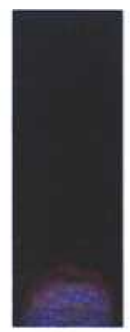

$54 \mathrm{~ms}$

a

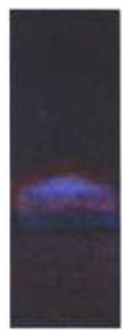

$66 \mathrm{~ms}$

$\mathrm{g}$

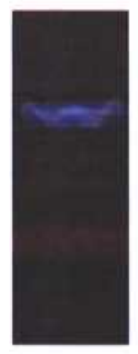

$82 \mathrm{~ms}$

m

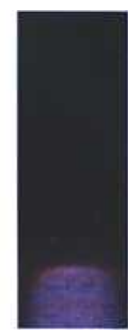

$56 \mathrm{~ms}$

b

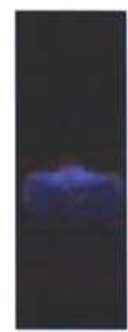

$68 \mathrm{~ms}$

h

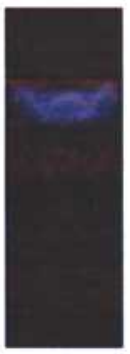

$84 \mathrm{~ms}$

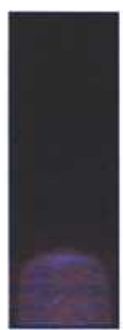

$58 \mathrm{~ms}$

c

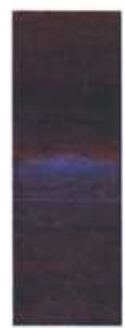

$72 \mathrm{~ms}$

$72 \mathrm{~ms}$
$\mathrm{i}$

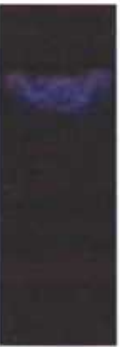

$86 \mathrm{~ms}$

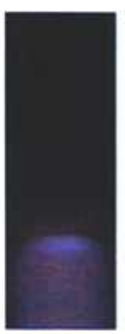

$60 \mathrm{~ms}$

d

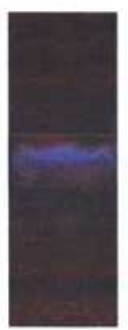

$74 \mathrm{~ms}$

j

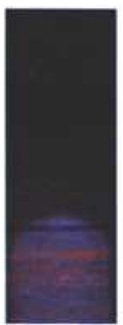

$62 \mathrm{~ms}$

c

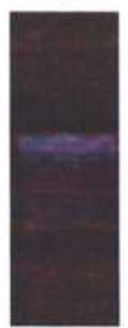

$76 \mathrm{~ms}$

k

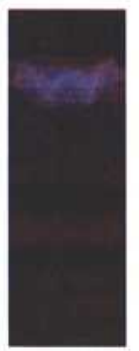

$88 \mathrm{~ms}$

p

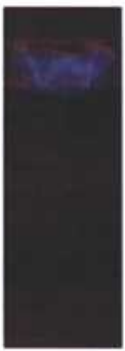

$90 \mathrm{~ms}$

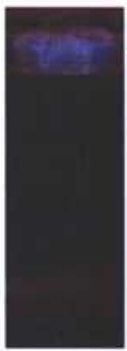

$94 \mathrm{~ms}$

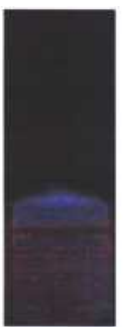

$64 \mathrm{~ms}$

f

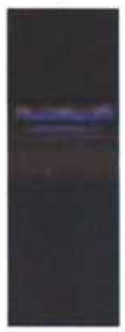

$80 \mathrm{~ms}$

I

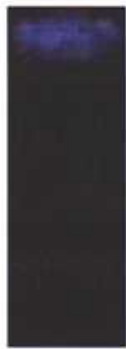

$96 \mathrm{~ms}$

Figure 7. Flame position and its shape as a function of time (upper half of tube). Combustion of propane/air mixture $\left(4.1 \% \mathrm{C}_{3} \mathrm{H}_{8}\right)$ in a vented tube with vent diameter of $50 \mathrm{~mm}$ $(\delta=7.7 \%), P_{v}=0.04 \mathrm{MPa} ; t_{v}=46 \mathrm{~ms}$.

process with continuously decreasing mass of the flammable mixture counteracts a sharp rise of pressure. Decreased mass of the mixture is responsible for low pressure and very short time of combustion.

The combustion process in a tube with small vent ratio $\delta=7.7 \%$ $(\phi 50 \mathrm{~mm})$ and high vent pressure (overpressure $p_{v}=0.18 \mathrm{MPa}$ ) is different from that in closed-tube combustion and in low-vent-pressure combustion (but the same vent ratio). The history of this process shown in Figures 5, 6, 


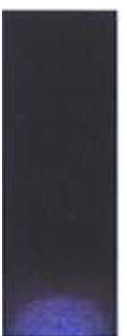

$60 \mathrm{~ms}$

a

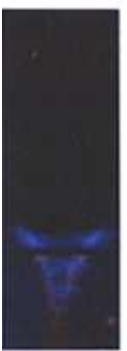

$100 \mathrm{~ms}$

g

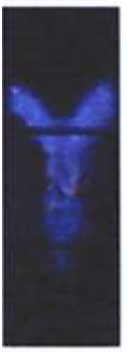

$118 \mathrm{~ms}$

m

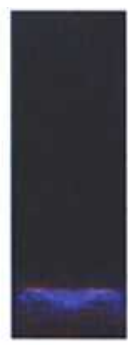

$70 \mathrm{~ms}$

b

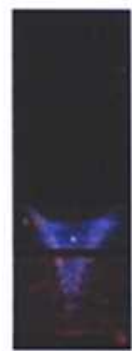

$108 \mathrm{~ms}$

h

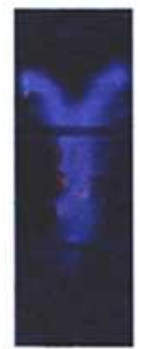

$120 \mathrm{~ms}$

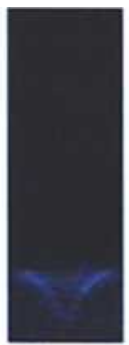

$80 \mathrm{~ms}$

c

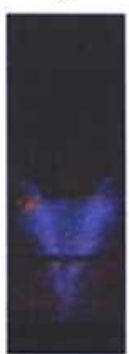

$110 \mathrm{~ms}$

i

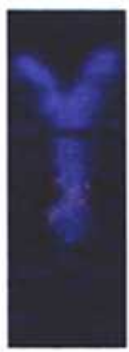

$122 \mathrm{~ms}$

o

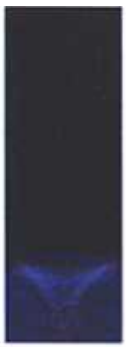

$82 \mathrm{~ms}$

d

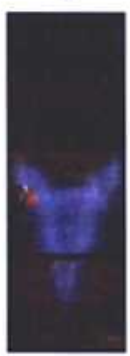

$112 \mathrm{~ms}$

j

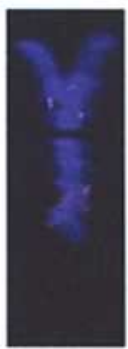

$124 \mathrm{~ms}$

p

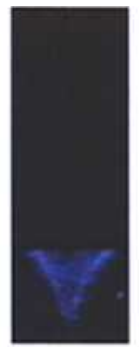

$90 \mathrm{~ms}$

c

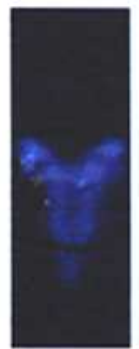

$114 \mathrm{~ms}$

k

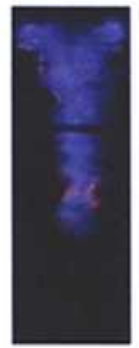

$126 \mathrm{~ms}$

q

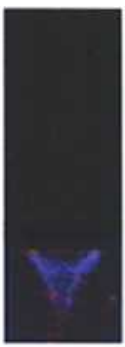

$92 \mathrm{~ms}$

f

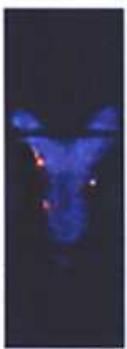

$116 \mathrm{~ms}$

I

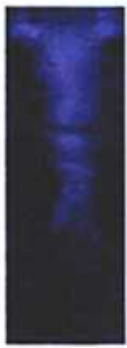

$128 \mathrm{~ms}$

Figure 8. Flame position and its shape as a function of time (upper half of tube). Combustion of propane/air mixture $\left(4.1 \% \mathrm{C}_{3} \mathrm{H}_{8}\right)$ in a vented tube with vent diameter of $50 \mathrm{~mm}$ $(\delta=7.7 \%), P_{v}=0.18 \mathrm{MPa}, t_{v}=110 \mathrm{~ms}$.

and 8 indicates that the initial development of combustion is the same as in closed-tube combustion up to the moment of venting $(t \approx 110 \mathrm{~ms}$ after ignition). Vent opening contributes to a small drop of pressure at the beginning of the process with the following fast opposite tendency during intensive outflow of the mixture from the tube. Increased outflow velocity intensifies combustion: the volume occupied by a tulip flame systematically grows. 
The flame becomes elongated and very thick with a developed cellular surface. It moves very fast to the vent. After approaching it, the heat release falls and the pressure dramatically decreases.

We can conclude that the high venting pressure is the main reason for a much higher discharge rate than before. Instantly increased venting flow interferes with very unstable tulip flame as it propagates in a short distance from the vent. This can explain intensification of the combustion process seen in the final frames of Figure 8.

Vent Diameter $100 \mathrm{~mm}(\boldsymbol{\delta}=30.8 \%)$. The experiments were carried out in a tube with vent diameter $100 \mathrm{~mm}$ and venting overpressures $0.005,0.02,0.05$, and $0.08 \mathrm{MPa}$. Pressure curves measured in these experiments are shown in Figure 9 and velocity variation of the flame-front leading point in Figure 10. History of flame propagation along the tube for overpressures $p_{v}=0.005 \mathrm{MPa}$ and $p_{v}=0.02 \mathrm{MPa}$ is shown in Figures 11 and 12, respectively. It is seen that the combustion process is very different from that characterizing closed-tube combustion. In all experiments considered here, vent opening is held at the

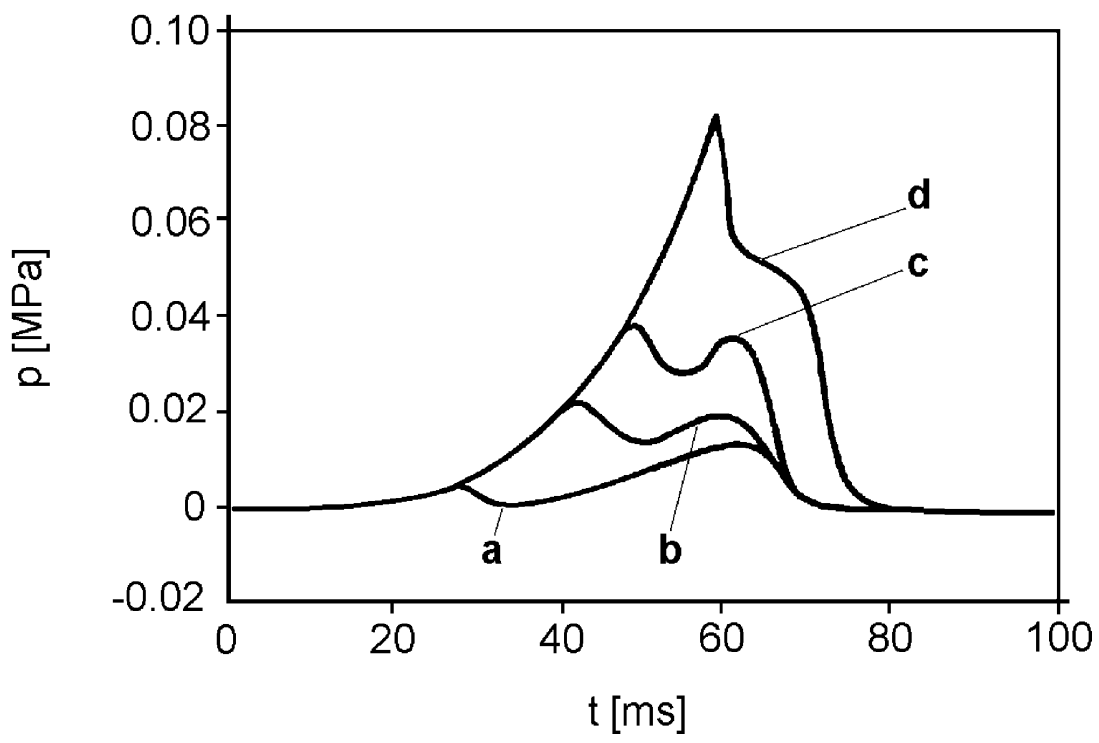

Figure 9. Pressure as a function of time in a tube with big vent diameter, $100 \mathrm{~mm}$ $(\delta=30.8 \%)$, for different values of overpressure: $\mathrm{a}, p_{v}=0.005 \mathrm{MPa} ; \mathrm{b}, p_{v}=0.02 \mathrm{MPa}$; , $p_{v}=0.05 \mathrm{MPa} ; \mathrm{d}, p_{v}=0.08 \mathrm{MPa}$. Combustion of propane/air mixture $\left(4.1 \% \mathrm{C}_{3} \mathrm{H}_{8}\right)$. 


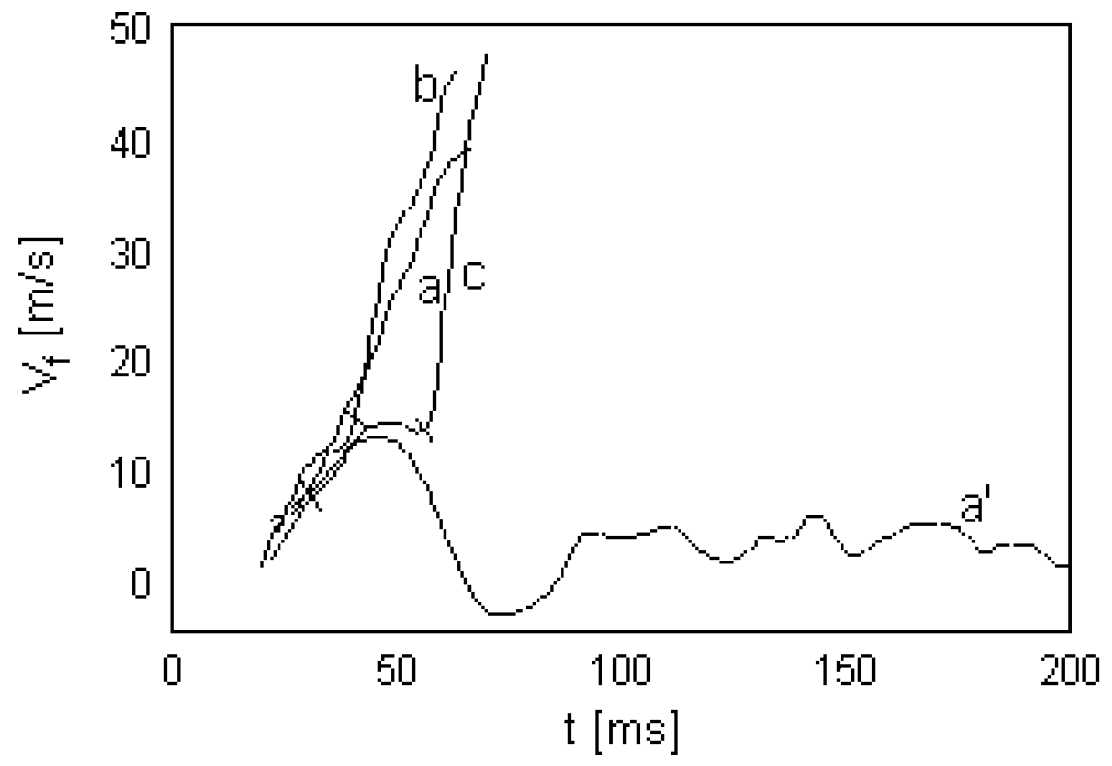

Figure 10. Velocity of flame-front leading point as a function of time for closed-tube combustion and venting combustion with $\delta=30.8 \%$ : $\mathrm{a}^{\prime}$, closed-tube combustion; a, $p_{v}=0.005 \mathrm{MPa} ; \mathrm{b}, p_{v}=0.02 \mathrm{MPa} ; \mathrm{c}, p_{v}=0.08 \mathrm{MPa}$. Combustion of propane/air mixture $\left(4.1 \% \mathrm{C}_{3} \mathrm{H}_{8}\right)$.

initial stage of flame propagation before formation of a developed tulip flame. After the vent is open, the flame behavior resembles that propagating from the closed end to the open end of the tube. The flame

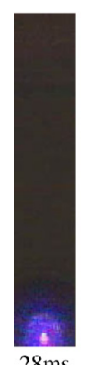

$28 \mathrm{~ms}$

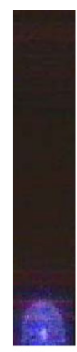

$32 \mathrm{~ms}$

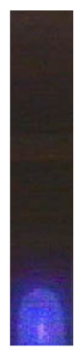

$36 \mathrm{~ms}$

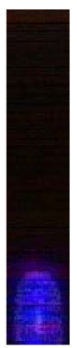

$40 \mathrm{~ms}$

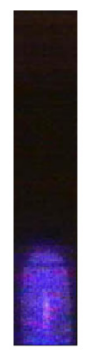

$44 \mathrm{~ms}$

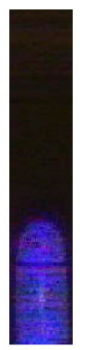

$48 \mathrm{~ms}$

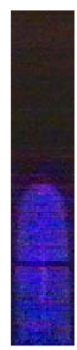

$52 \mathrm{~ms}$

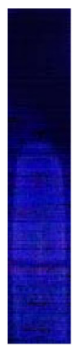

$56 \mathrm{~ms}$

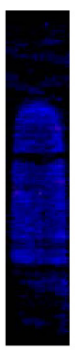

$60 \mathrm{~ms}$

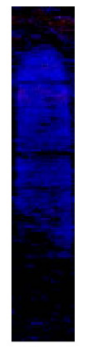

$64 \mathrm{~ms}$

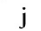

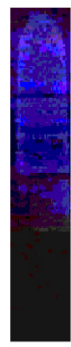

$68 \mathrm{~ms}$ k

Figure 11. Flame position and its shape as a function of time (full-length tube). Combustion of propane/air mixture $\left(4.1 \% \mathrm{C}_{3} \mathrm{H}_{8}\right)$ in a vented tube with vent diameter of $100 \mathrm{~mm}$ $(\delta=30.8 \%), P_{v}=0.005 \mathrm{MPa}, t_{v}=28 \mathrm{~ms}$. 


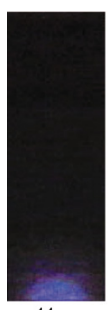

$44 \mathrm{~ms}$

a

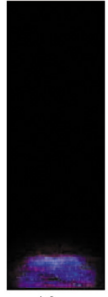

$46 \mathrm{~ms}$

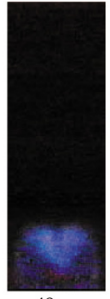

$48 \mathrm{~ms}$

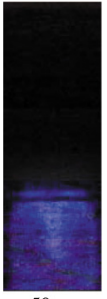

$50 \mathrm{~ms}$

d

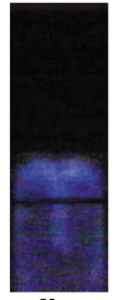

$52 \mathrm{~ms}$

e

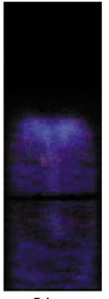

$54 \mathrm{~ms}$

f

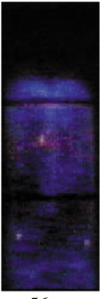

$56 \mathrm{~ms}$

$\mathrm{g}$

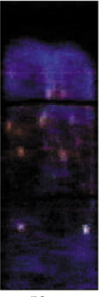

$58 \mathrm{~ms}$

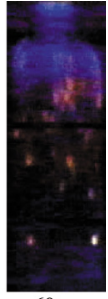

$60 \mathrm{~ms}$

Figure 12. Flame position and its shape as a function of time (upper-half of tube). Combustion of propane/air mixture $\left(4.1 \% \mathrm{C}_{3} \mathrm{H}_{8}\right)$ in a vented tube with vent diameter of $100 \mathrm{~mm}$ $(\delta=30.8 \%), P_{v}=0.02 \mathrm{MPa}, t_{v}=41 \mathrm{~ms}$.

moves along the tube very fast irrespective of venting overpressure (see Figure 10). Flame shape and character of combustion depend on venting delay time. Early venting generates an elongated ellipsoidal flame shape with accompanying surface combustion (Figure 11). More delayed venting elevates initial pressure and modifies the character of combustion. Later venting makes it possible to initiate formation of a tulip flame (see Figure 13, frames b, c, d) changing the mechanism of combustion from the pure surface combustion to the mixed surface and volume combustion. At the final stage of combustion, the flame front enters the vent and it obstructs the outflow of the flammable mixture by the low-density combustion gases. This results in transitory pressure increase.
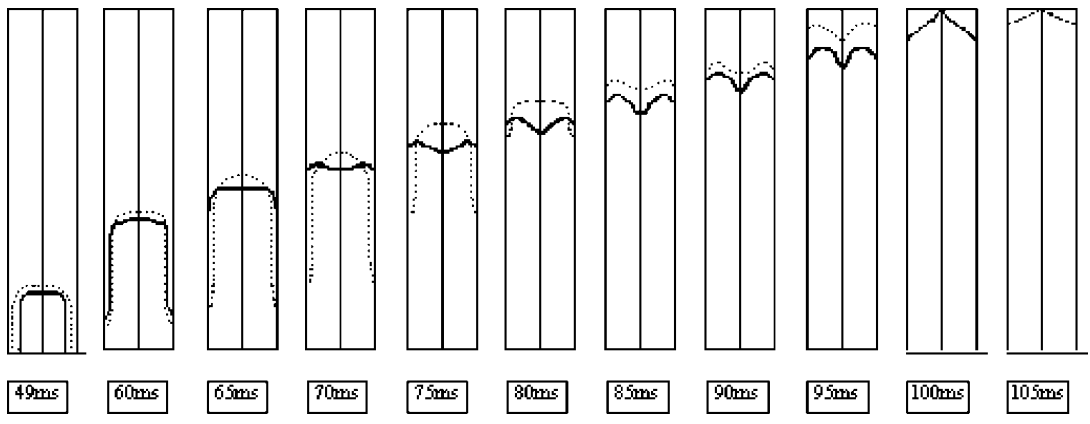

$105 \mathrm{~ms}$

Figure 13. Comparison of measured and calculated flame-front shape evolution in a vented vessel $\left(\delta=7.7 \%, p_{v}=0.02 \mathrm{MPa}, t_{v}=49 \mathrm{~ms}\right)$. Solid lines, measurements; dotted lines, calculations. 


\section{NUMERICAL SIMULATION OF COMBUSTION WITH VENTING}

\section{Mathematical Model and Algorithm}

A combustion process of premixed propane/air mixture $\left(4.1 \% \mathrm{C}_{3} \mathrm{H}_{8}\right)$ in a cylindrical tube the same as in experiments is considered. The same vent ratios and venting pressure parameters were used for simulation. The computational fluid dynamics software Fluent was used to perform the simulation. The ignition and venting conditions adopted in the study are also the same as those in the experiments. A mathematical model capable of predicting the reacting compressible flows was formulated based on the following assumptions: the system is axisymmetrical, the flammable mixture is quiescent and homogeneous; the reaction is simplified as a global one-step irreversible process, and radiation is ignored. The calculations are carried out for an unsteady, turbulent, compressible and reacting flow. The well-known $k-\varepsilon$ turbulence model is utilized and the mean conservation equations take the following forms (Launder and Spalding, 1974):

$$
\begin{aligned}
& \frac{\partial}{\partial t} \rho+\frac{\partial}{\partial \boldsymbol{x}}(\rho \boldsymbol{u})+\frac{1}{\boldsymbol{r}} \frac{\partial}{\partial \boldsymbol{r}}(\rho \boldsymbol{v})=\mathbf{0} \\
& \frac{\partial}{\partial \boldsymbol{t}}(\rho \boldsymbol{u})+\frac{\partial}{\partial \boldsymbol{x}}(\rho \boldsymbol{u} \boldsymbol{u})+\frac{1}{\boldsymbol{r}} \frac{\partial}{\partial \boldsymbol{r}}(\rho \boldsymbol{v} \boldsymbol{u})=\frac{\partial}{\partial \boldsymbol{x}}\left(\mu_{\mathrm{eff}} \frac{\partial \boldsymbol{u}}{\partial \boldsymbol{x}}\right)+\frac{1}{\boldsymbol{r}} \frac{\partial}{\partial \boldsymbol{r}}\left(\boldsymbol{r} \mu_{\mathrm{eff}} \frac{\partial \boldsymbol{u}}{\partial \boldsymbol{r}}\right) \\
& -\frac{\partial p}{\partial \boldsymbol{x}}+\frac{\partial}{\partial \boldsymbol{x}}\left[\mu_{\mathrm{eff}}\left(\frac{\partial \boldsymbol{u}}{\partial \boldsymbol{x}}-\frac{2}{3}(\nabla \cdot \vec{V})\right)\right] \\
& +\frac{1}{r} \frac{\partial}{\partial \boldsymbol{r}}\left(r \mu_{\mathrm{eff}} \frac{\partial v}{\partial x}\right)-\rho g \\
& \frac{\partial}{\partial \boldsymbol{t}}(\rho \boldsymbol{v})+\frac{\partial}{\partial \boldsymbol{x}}(\rho \boldsymbol{u v})+\frac{1}{\boldsymbol{r}} \frac{\partial}{\partial \boldsymbol{r}}(\rho \boldsymbol{v} \boldsymbol{v})=\frac{\partial}{\partial \boldsymbol{x}}\left(\mu_{\mathrm{eff}} \frac{\partial \boldsymbol{v}}{\partial \boldsymbol{x}}\right)+\frac{1}{\boldsymbol{r}} \frac{\partial}{\partial \boldsymbol{r}}\left(\boldsymbol{r} \mu_{\mathrm{eff}} \frac{\partial \boldsymbol{v}}{\partial \boldsymbol{r}}\right) \\
& -\frac{\partial \boldsymbol{p}}{\partial \boldsymbol{r}}+\frac{\partial}{\partial \boldsymbol{x}}\left(\mu_{\mathrm{eff}} \frac{\partial \boldsymbol{u}}{\partial \boldsymbol{r}}\right) \\
& +\frac{1}{r} \frac{\partial}{\partial \boldsymbol{r}}\left[\boldsymbol{r} \mu_{\mathrm{eff}}\left(\frac{\partial \boldsymbol{v}}{\partial \boldsymbol{r}}-\frac{2}{3}(\nabla \cdot \vec{V})\right)\right] \\
& \frac{\partial}{\partial t}\left(\rho c_{p} T\right)+\frac{\partial}{\partial x}\left(\rho u c_{p} T\right)+\frac{1}{r} \frac{\partial}{\partial r}\left(\rho v c_{p} T\right) \\
& =\frac{\partial}{\partial x}\left(k_{\text {eff }} \frac{\partial T}{\partial x}+\sum_{i^{\prime}}\left(\rho D_{\text {eff }} \frac{\partial \boldsymbol{m}_{i^{\prime}}}{\partial \boldsymbol{x}} \int \boldsymbol{c}_{p, i^{\prime}} \mathbf{d} T\right)\right) \\
& +\frac{1}{r} \frac{\partial}{\partial \boldsymbol{r}}\left[\boldsymbol{r}\left(\boldsymbol{k}_{\mathrm{eff}} \frac{\partial T}{\partial \boldsymbol{r}}+\sum_{i^{\prime}}\left(\rho D_{\mathrm{eff}} \frac{\partial \boldsymbol{m}_{i^{\prime}}}{\partial \boldsymbol{r}} \int \boldsymbol{c}_{p, i^{\prime}} \mathbf{d} T\right)\right)\right]+\bar{w} \cdot Q
\end{aligned}
$$


The equation of state and the mass balance equation for each reactive species are

$$
\begin{aligned}
p & =\rho R T \sum_{i^{\prime}} m_{i^{\prime}} / M_{i^{\prime}} \\
\frac{\partial}{\partial t}\left(\rho m_{i^{\prime}}\right)+\frac{\partial}{\partial x}\left(\rho u m_{i^{\prime}}\right)+\frac{1}{r} \frac{\partial}{\partial r}\left(\rho v m_{i^{\prime}}\right) & =\frac{\partial}{\partial x}\left(\rho D_{e f f} \frac{\partial m_{i^{\prime}}}{\partial x}\right) \\
& +\frac{1}{r} \frac{\partial}{\partial r}\left(r \rho D_{e f f} \frac{\partial m_{i^{\prime}}}{\partial r}\right)+\bar{w}_{s, i^{\prime}}
\end{aligned}
$$

According to the $k-\varepsilon$ model, the effective transport coefficients in the preceding equations have the following relations:

$$
\begin{gathered}
\mu_{\mathrm{eff}}=\mu_{l}+\mu_{t} \quad \mu_{l}=\sum_{i^{\prime}} \frac{X_{i^{\prime}} \mu_{i^{\prime}}}{\sum_{j^{\prime}} X_{j^{\prime}} \phi_{i^{\prime}, j^{\prime}}} \quad \mu_{t}=c_{\mu} \rho \frac{k^{2}}{\varepsilon} \quad c_{\mu}=0.09 \\
k_{\mathrm{eff}}=k_{l}+k_{t} \quad k_{l}=\sum_{i^{\prime}} \frac{X_{i^{\prime}} k_{i^{\prime}}}{\sum_{j^{\prime}} X_{j^{\prime}} \phi_{i^{\prime}, j^{\prime}}} \quad k_{t}=\frac{\mu_{t} c_{P}}{\sigma_{T}} \quad \sigma_{T}=0.9 \\
D_{\text {eff }}=D_{l}+D_{t} \quad D_{l}=2.88 \times 10^{-5}\left(\mathrm{~m}^{2} / \mathrm{s}\right) \quad D_{t}=\frac{\mu_{t}}{\rho S c_{t}} \quad S c_{t}=0.7
\end{gathered}
$$

The turbulence kinetic energy $k$ and its rate of dissipation, $\varepsilon$, are obtained from the following transport equations:

$$
\begin{aligned}
\frac{\partial}{\partial \boldsymbol{t}}(\rho \boldsymbol{k})+\frac{\partial}{\partial \boldsymbol{x}}(\rho \boldsymbol{u k})+\frac{1}{\boldsymbol{r}} \frac{\partial}{\partial \boldsymbol{r}}(\rho \boldsymbol{v} \boldsymbol{k})= & \frac{\partial}{\partial \boldsymbol{x}}\left[\left(\mu+\frac{\mu_{t}}{\sigma_{k}}\right) \frac{\partial \boldsymbol{k}}{\partial \boldsymbol{x}}\right] \\
& +\frac{1}{\boldsymbol{r}} \frac{\partial}{\partial \boldsymbol{r}}\left[\boldsymbol{r}\left(\mu+\frac{\mu_{t}}{\sigma_{k}}\right) \frac{\partial \boldsymbol{k}}{\partial \boldsymbol{r}}\right] \\
& +\boldsymbol{G}_{\boldsymbol{k}}+G_{b}-\rho \varepsilon \\
\frac{\partial}{\partial \boldsymbol{t}}(\rho \varepsilon)+\frac{\partial}{\partial \boldsymbol{x}}(\rho \boldsymbol{u} \varepsilon)+\frac{1}{\boldsymbol{r}} \frac{\partial}{\partial \boldsymbol{r}}(\rho \boldsymbol{v} \varepsilon)= & \frac{\partial}{\partial \boldsymbol{x}}\left[\left(\mu+\frac{\mu_{t}}{\sigma_{\varepsilon}}\right) \frac{\partial \varepsilon}{\partial \boldsymbol{x}}\right] \\
& +\frac{1}{\boldsymbol{r}} \frac{\partial}{\partial \boldsymbol{r}}\left[\boldsymbol{r}\left(\mu+\frac{\mu_{t}}{\sigma_{\varepsilon}}\right) \frac{\partial \varepsilon}{\partial \boldsymbol{r}}\right] \\
& +\frac{\varepsilon}{\boldsymbol{k}}\left(\boldsymbol{c}_{1} \boldsymbol{G}_{\boldsymbol{k}}-\boldsymbol{c}_{2} \rho \varepsilon\right)
\end{aligned}
$$

The model constants $C_{1 \varepsilon}, C_{2 \varepsilon}, C_{\mu}, \sigma_{K}$, and $\sigma_{\varepsilon}$ take the following values as recommended in Fluent (1999):

$$
C_{1 \varepsilon}=1.44 \quad C_{2 \varepsilon}=1.92 \quad C_{\mu}=0.09 \quad \sigma_{K}=1.0 \quad \sigma_{\varepsilon}=1.3
$$


The specific heat capacity of the mixture is defined as a function of composition:

$$
c_{p}=\sum_{i^{\prime}} \boldsymbol{m}_{i^{\prime}} c_{p, i^{\prime}}
$$

The specific heat capacity of each chemical species is a function of temperature with a piecewise polynomial:

$c_{p, i^{\prime}}(T)=\left\{\begin{array}{lc}A_{i, 0}+A_{i, 1} T^{1}+A_{i, 2} T^{2}+A_{i, 3} T^{3}+A_{i, 4} T^{4} & 300 \mathrm{~K} \leq T<1000 \mathrm{~K} \\ B_{i, 0}+B_{i, 1} T^{1}+B_{i, 2} T^{2}+B_{i, 3} T^{3}+B_{i, 4} T^{4} & 1000 \mathrm{~K} \leq T \leq 5000 \mathrm{~K}\end{array}\right.$

The so-called Arrhenius-EBU (Eddy-Break-Up) model (Magnussen and Hjertager, 1976) was adopted to predict the turbulent premixed combustion. The time-averaged reaction rate is determined by the following relation:

$$
\bar{w}_{s}=\min \left[\bar{w}_{s A}, \bar{w}_{s t}\right]
$$

where $\bar{w}_{s A}$ and $\bar{w}_{s t}$ are Arrhenius kinetic rate and EBU reaction rate, respectively; they are determined from the literature (Fluent, 1999; McBride et al., 1993; Rose and Cooper, 1977; Spalding, 1970; Westbrook and Dryer, 1981).

The computation was performed for a cylindrical vessel of $0.18 \mathrm{~m}$ inner diameter and $1 \mathrm{~m}$ length. The walls were assumed to be adiabatic. A given static pressure value is specified at the vent as boundary conditions. When the flow becomes locally supersonic, pressure and other flow quantities are extrapolated from the interior flow field.

Spatial discretization is performed with a finite-volume technique, and time discretization uses the Gauss-Seidel one-order implicit approach. The structured body-fitted grid scheme and the solutiongradient-adaptive technique were adopted to improve the flame capture and reduce the numerical error. Flow-field grid size is $5 \mathrm{~mm} \times 5 \mathrm{~mm}$, totaling the grid number of $18 \times 200$. To determine the flame-front temperature, $T$ was taken as the gradient function in the solution-gradientadaptive technique and the grid size was $1 \mathrm{~mm} \times 1 \mathrm{~mm}$.

The details of the modeling are available in the work of $\mathrm{Hu}$ (2001).

\section{Validation of Mathematical Modeling}

Comparison of measured and calculated combustion pressure history is shown in Figure 14. It is seen from these comparisons that the numerical simulation can successfully reproduce the main features of the analyzed 

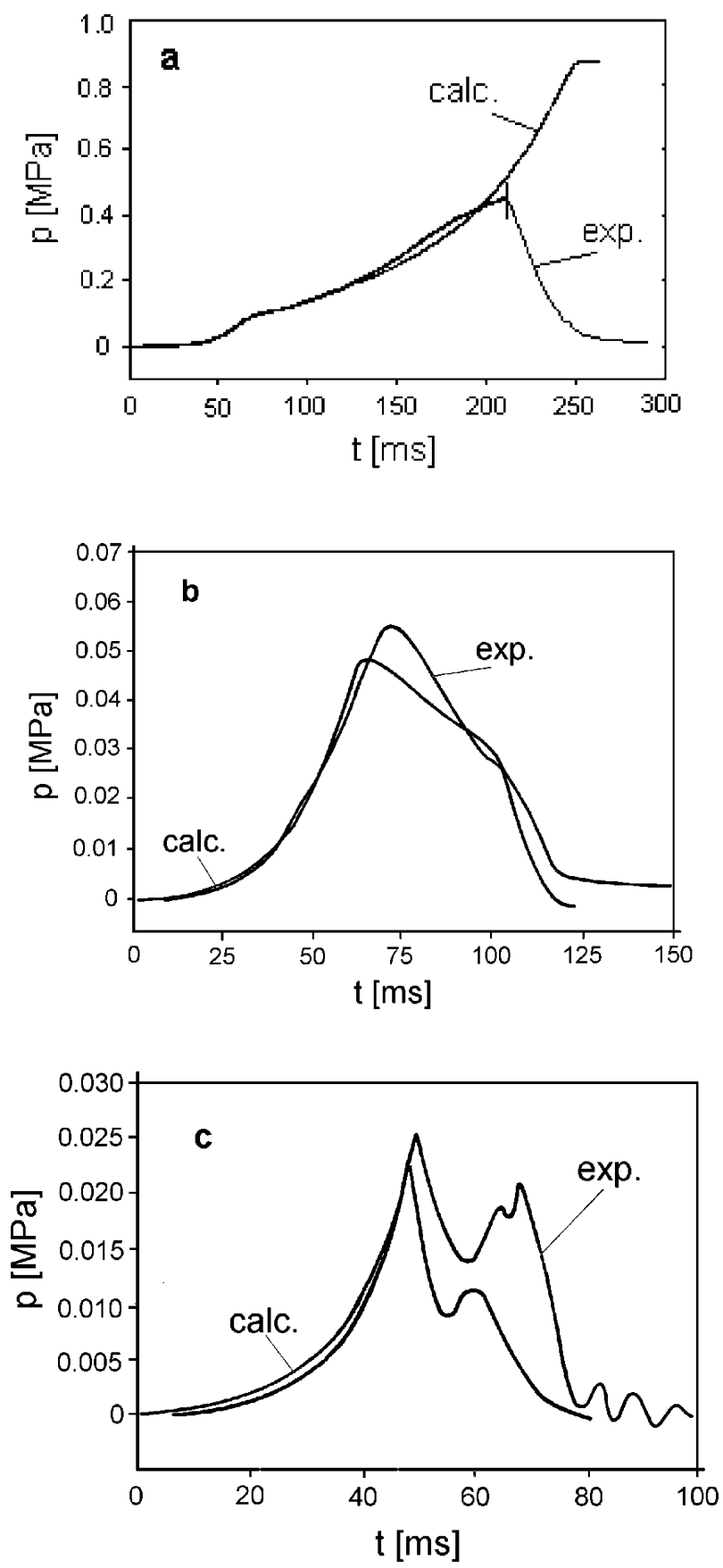
combustion process, though quantitatively there still exists a discrepancy between measurements and the computed results. The comparison of measured and calculated flame-front evolution in a vented vessel is illustrated in Figure 13. It is seen that the motion of the calculated flame front along the tube is a bit slower than that determined in measurements. Small discrepancies are due to various simplifying assumptions made in the model, although the main characteristics of the process such as pressure history and flame shape evolution are similar. Finally, it can be concluded that the mathematical model can be used for the analysis of the flow field and the interaction of the flow with the flame.

\section{Simulation of Venting Process}

Elucidation of the experiments is the main advantage of the simulation methods. Only a few simulation results are addressed here as examples.

The temperature profiles along the axis of the tube were calculated in a closed and vented vessel. In Figure $15 a$ we can see temperature distribution typical for a constant-volume combustion, in which the Maché effect, namely the temperature rise due to adiabatic compression, is clearly seen. Comparing the temperature curves in Figures $15 b$ and $15 c$, we can see very clearly the difference in venting process for a small and big vent. In a tube with a big vent, the flame propagates much faster and the combustion is more violent. Simulation of the flow in vented tubes is shown in Figures 16 and 17.

Streamlines of the venting process in a tube with vent diameter $50 \mathrm{~mm}$, at $0.02 \mathrm{MPa}$ venting pressure and $49 \mathrm{~ms}$ venting time, are shown in Figure 16. The flame shape evolves from semispherical into an elongated semi-ellipsoidal before it approaches the sidewall. The flame front inside the vessel is driven by the expansion of high-temperature combustion gases and flow induced by venting. Velocity vectors are directed toward the vent end. The process can be considered adiabatic.

In a short time after ignition $(55-60 \mathrm{~ms})$, the expanding cylindrical flame front touches the sidewall of the vessel. Due to the quenching

Figure 14. Combustion pressure as a function of time: a, closed tube, experimental curve represents closed tube only to a moment of pressure rise up to $0.46 \mathrm{MPa}$; $b$, tube with vent diameter $50 \mathrm{~mm}$, venting overpressure $p_{v}=0.005 \mathrm{MPa}$, and venting delay time $t_{v}=49 \mathrm{~ms} ; \mathrm{c}$, tube with vent diameter $100 \mathrm{~mm}$, venting overpressure $p_{v}=0.005 \mathrm{MPa}$, and venting delay time $t_{v}=49 \mathrm{~ms}$. 

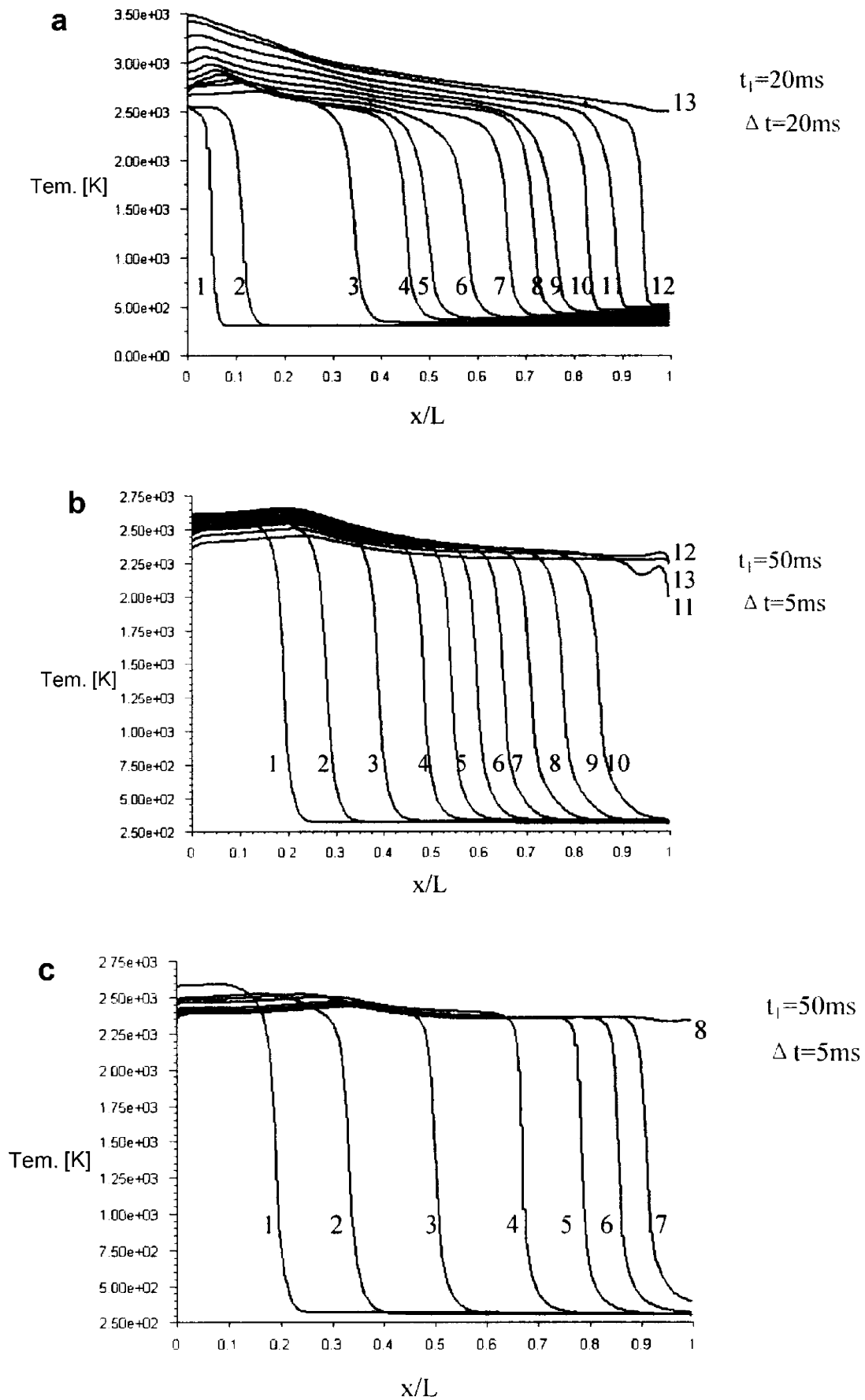

Figure 15. Temperature profiles along the axis of the tube varied with time during the combustion process of closed and vented vessels in $4.1 \%$ propane/air mixture. 


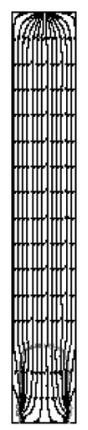

$50 \mathrm{~ms}$

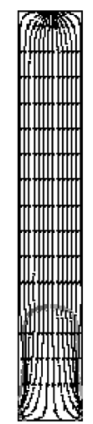

$55 \mathrm{~ms}$

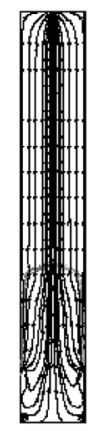

$60 \mathrm{~ms}$

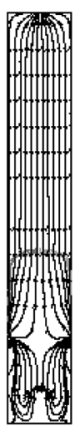

$62 \mathrm{~ms}$

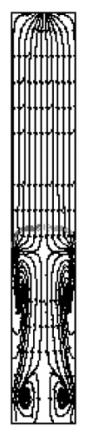

$65 \mathrm{~ms}$

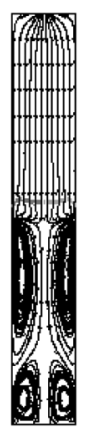

$70 \mathrm{~ms}$

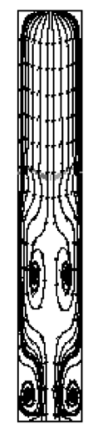

$75 \mathrm{~ms}$
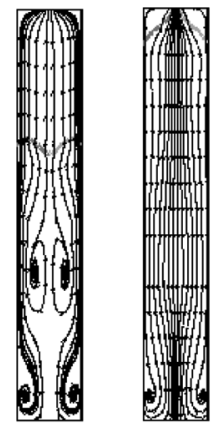

$80 \mathrm{~ms}$

$100 \mathrm{~ms}$

Figure 16. Calculated flow field during vented combustion $\left(\delta=7.7 \%, p_{v}=0.02 \mathrm{MPa}\right.$, $\left.t_{v}=49 \mathrm{~ms}\right)$.

effect of the wall, the lateral part of the flame front disappears quickly and its preserved part is gradually flattened. The sharp decrease of the flame-front surface results in a significant reduction of the amount of expanding burned gases and follows with a decrease of pressure. Then the burned zone is divided into two reverse-flow regions around the contact surface of the lateral flame front with the wall $(62 \mathrm{~ms})$ : part of the gases flows toward the ignition end but new burned gases are generated and they push the flame front toward the unburned mixture. When the lateral flame front disappears completely $(70 \mathrm{~ms})$, gas in the burned zone flows in a direction opposite to flame propagation. At the ignition end of the tube the flow creates vortex ring.

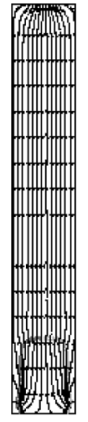

$50 \mathrm{~ms}$

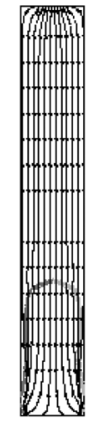

$55 \mathrm{~ms}$

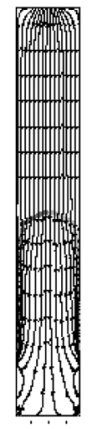

$60 \mathrm{~ms}$
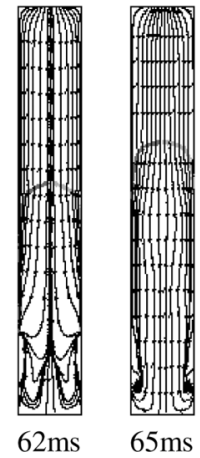
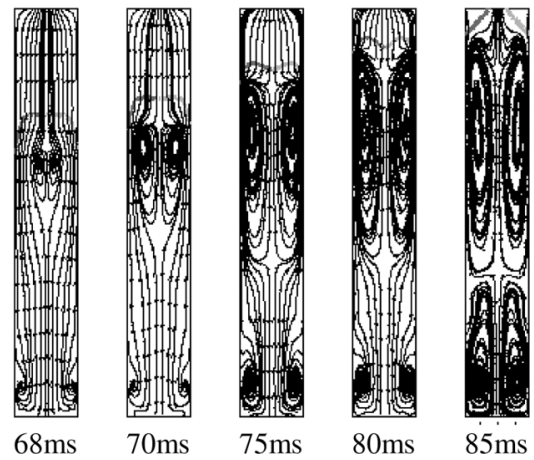

Figure 17. Calculated flow field during vented combustion $\left(\delta=30.8 \%, p_{v}=0.02 \mathrm{MPa}\right.$, $t_{v}=49 \mathrm{~ms}$ ). 
Through the process of its development, the flame front is finally transformed into a tulip shape. This shape is influenced by a drag effect of venting outflow. The flow in the burned zone changes to the venting flow direction and a symmetrical vortex ring is created in the central region of the tube.

Streamlines of the venting process in a tube with diameter $100 \mathrm{~mm}$ at $0.02 \mathrm{MPa}$ venting pressure and $49 \mathrm{~ms}$ venting time are shown in Figure 17.

Comparison of Figures 16 and 17 indicates that the common feature of both analyzed combustion pictures is the appearance of tulip-flame shape. Because venting flow in a tube with a $100-\mathrm{mm}$ venting orifice is much stronger than that in a tube with a $50-\mathrm{mm}$ orifice, the flame-front deformation and flame propagation are faster. It can be noticed that gas flows in burned and unburned zones toward the venting orifice. At the last stage of the venting process, two elongated axial-symmetric vortex rings are dominated in the burned zone.

\section{CONCLUDING REMARKS}

Simultaneous record of pressure and flame pictures enables us to examine the flame behavior both in a closed and vented vessel. The combustion process in a vented vessel can be analyzed in terms of vent pressure and ratio of vent area. Some conclusions can be drawn from such an examination:

1. Combustion in a closed cylindrical vessel is identified as a well-known three-stage process. The first stage of combustion is adiabatic in nature; its termination is indicated on the pressure curve by the maximum value of $\mathrm{d} p / \mathrm{d} t$. The second stage is accompanied by a rapidly decreased flame surface (extinction of the flame on the wall); its appearance is indicated on the pressure curve by a decreased value of $\mathrm{d} p / \mathrm{d} t$. The third stage is characterized by instability phenomena resulting in complex deformation of the flame during its propagation to the end of the tube.

2. Venting softens the flame instability effects. The vent area is more effective in damping of flame instability than vent pressure.

3. Interaction between vent induced flow and combustion can be characterized in the following way: 
- When the vent induced flow is weak, which corresponds to the cases of small vent area ratio and low/medium vent pressure, the combustion process is similar to that with the flame propagating from the closed to the open end of the tube. The pressure continues to go up, and the flame surface remains smooth, clear, and thin ellipsoidal. The propagation velocity is higher than that in a closed vessel except for the final stage when flame goes out of the vessel.

- When the vent induced flow is strong, which corresponds to the cases of high vent pressure for small vent area and big vent area, the interactions between vent induced flow and the flame is strong. Combustion is intensified and the flame accelerates. Increased combustion rate generates a transient pressure rise.

- The proposed numerical model satisfactorily simulates the main features of combustion in closed and vented vessels such as pressure variation pattern, flame propagation velocity, and flame configuration. Simulated temperature and velocity distribution are very useful pieces of information, because they are not available from experiments.

\section{REFERENCES}

Canu, P., Rota, R., and Carra, S. (1991) Vented gas deflagrations modeling: A simplified approach. Combust. Flame, 85, 319-330.

Clanet, C. and Searby, G. (1996) On the "tulip flame" phenomenon. Combust. Flame, 105, 225-238.

Cooper, M.G., Fairweather, M., and Tite, J.P. (1986) On the mechanisms of pressure generation in vented explosion. Combust. Flame, 65, 1-14.

Eckhoff, R.K. (1991) Dust Explosions in the Process Industries, ButterworthHeinemann, Oxford, UK.

Fluent 5.4 (1999) Product Document and User Manuals. Fluent Inc., Lebanon, NH.

Gonzales, M. (1996) Acoustic instability of a premixed flame propagating in a tube. Combust. Flame, 107, 245-259.

Gonzalez, M., Borghi, R., and Saouab, A. (1992) Interaction of a flame front with its self-generated flow in an enclosure: The "tulip flame" phenomenon. Combust. Flame, 88, 201-220.

$\mathrm{Hu}, \mathrm{J}$. (2001) A Study on the Mechanisms of Explosion Venting in Cylindrical Vessel with Large Aspect Ratio. Ph.D. Dissertation, Institute of Mechanics, Chinese Academy of Sciences, Beijing (in Chinese).

Launder, B.E. and Spalding, D.B. (1974) The numerical computation of turbulent flows. Comput. Methods Appl. Mech. Eng., 3, 269-289. 
Magnussen, B.F. and Hjertager, B.H. (1976) On mathematical modeling of turbulent combustion with special on soot formation and combustion. Proc. Combust. Instit., 16, 719-730.

Markstein, G.H. (1964) Nonsteady Flame Propagation, Pergamon Press, Oxford, pp. 113-119.

McBride, B.J., Gordon, S., and Reno, M.A. (1993) Coefficients for Calculating Thermodynamic and Transport Properties of Individual Species. NASA TM4513.

McCann, D.P.J., Thomas, G.O., and Edwards, D.H. (1985) Gasdynamics of vented explosions. Part I: experimental studies. Combust. Flame, 59, 233250.

Nagy, J. and Verakis, C. (1983) Development and Control of Dust Explosions, Marcel Dekker, New York.

Pu, Y.K. (1987) Fundamental Characteristics of Laminar and Turbulent Flames in Cornstarch Dust-Air Mixture. Ph.D. Dissertation, McGill University, Montreal.

Rose, J.W. and Cooper, J.R. (1977) Technical Data on Fuels, 7th ed., Wiley, London, UK.

Spalding, D.B. (1970) Mixing and chemical reaction in steady confined turbulent flame. Proc. Combust. Instit., 13, 649-657.

Starke, R. and Roth, P. (1986) An experimental investigation of flame behavior during cylindrical vessel explosions. Combust. Flame, 66, 249-259.

Swift, I. and Epstein, M. (1987) The performance of low-pressure explosions vents Plant/Op. Prog., 6, 98-105.

Westbrook, C. and Dryer, F. (1981) Simplified reaction mechanisms for oxidation of hydrocarbon fuels in flames. Combust. Sci. Technol., 27, 31-43. 